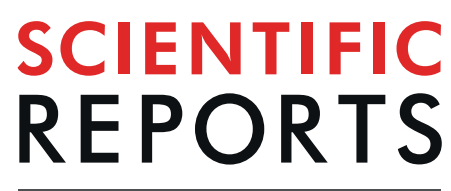

\title{
High yield conversion of biowaste coffee grounds into hierarchical porous carbon for superior capacitive energy storage
}

\author{
Xiaoguang Liu, Shuai Zhang, Xin Wen ${ }^{*}$, Xuecheng Chen ${ }^{*}$, Yanliang Wen, Xiaoze Shi \& \\ Ewa Mijowska
}

Recently great efforts have been focused on converting biowastes into high-valued carbon materials. However, it is still a great challenge to achieve high carbon yield and controllable porous distribution in both industrial and academic research. Inspired by the multi-void structure of waste coffee grounds, herein we fabricated hierarchical porous carbon via the combination of catalytic carbonization and alkali activation. The catalytic carbonization process was applied to obtain well-defined mesoporous carbon with carbon yield as high as $\mathbf{4 2 . 5} \mathrm{wt} \%$, and subsequent alkali activation process produced hierarchical porous carbon with ultrahigh specific surface area $\left(3549 \mathrm{~m}^{2} \mathrm{~g}^{-1}\right)$ and large meso-/macropores volume $\left(1.64 \mathrm{~cm}^{3} \mathrm{~g}^{-1}\right)$. In three-electrode system, the electrode exhibited a high capacitance of $440 \mathrm{~F} \mathrm{~g}^{-1}$ at $0.5 \mathrm{Ag}^{-1}$ in $6 \mathrm{M} \mathrm{KOH}$ aqueous electrolyte, superior to that of many reported biomass-derived porous carbons. In two-electrode system, its energy density reached to $101 \mathrm{Wh} \mathrm{kg}^{-1}$ at the power density of $900 \mathrm{~W} \mathrm{~kg}^{-1}$ in 1-Ethyl-3-Methylimidazolium Tetrafluoroborate $\left(\mathrm{EMIMBF}_{4}\right)$. This work provided a cost-effective strategy to recycle biowastes into hierarchical porous carbon with high yield for highperformance energy storage application.

In recent years, with the purpose of turning waste into treasure and reducing environmental hazard, waste management for the production of high-valuable carbon materials has received considerable attention ${ }^{1}$. Specially, biowastes are viewed as the most outstanding natural carbon precursors by virtue of their rich source, low-cost and sustainability ${ }^{2-4}$. So far, many biowastes have been recycled to synthesize carbon materials, but their applications are still limited by low carbon yield and unsatisfied pore structure ${ }^{5-7}$. Thus, effective methods are necessary to control carbonization process and optimize pore distribution for meeting the demands of various intended applications.

Until now, several strategies have been developed for the fabrication of porous carbons, including hydrothermal carbonization ${ }^{8}$, hard template ${ }^{9}$ and molten-salt route ${ }^{10}$, etc. Generally the widely used carbon-rich precursors are polymers ${ }^{11}$, metal-organic frameworks ${ }^{12}$, organic complex ${ }^{13}$ and carbohydrates ${ }^{14}$. Meanwhile, natural biomass is also widely used as carbon precursors, such as salvia splendens ${ }^{15}$, clover stems ${ }^{16}$, moringa oleifera branches ${ }^{17}$, ginkgo leaves ${ }^{18}$, and pollens ${ }^{19}$. Moreover, with considering environmental protection and resource recycle, biowastes are viewed as more promising natural carbon precursors ${ }^{20}$. Currently, various biowastes from plants or animals have been used for porous carbons production, such as kraft $\operatorname{lignin}^{21}$, soybean residue ${ }^{22}$, dairy manure ${ }^{23}$, bagasse wastes ${ }^{24}$ and peanut shell ${ }^{1}$. In many cases, the added catalysts (or activators) are difficult to penetrate into the inside of carbon precursors, resulting in low carbon yield and unmanageable pore distribution ${ }^{25}$. Besides, many kinds of biowastes are difficult to collect or have a low production. It is therefore paramount to exploit low-cost and widely-distributed biowastes as carbon precursors, followed by effective catalytic-carbonization process and optimize pore size distribution for achieving high carbon yield and controllable porous structure.

As an important energy-storage device, supercapacitor has been attracting significant interest due to its intrinsic advantages of high power density, rapid charge-discharge rate and excellent cycling stability ${ }^{26-28}$. The principle of supercapacitor is a quick charge accumulation and release process in the interface of electrode-electrolyte,

Nanomaterials Physicochemistry Department, Faculty of Chemical Technology and Engineering, West Pomeranian University of Technology Szczecin, al. Piastów 45, 70-311, Szczecin, Poland. *email: hgwenxin@126.com; xchen@ zut.edu.pl 


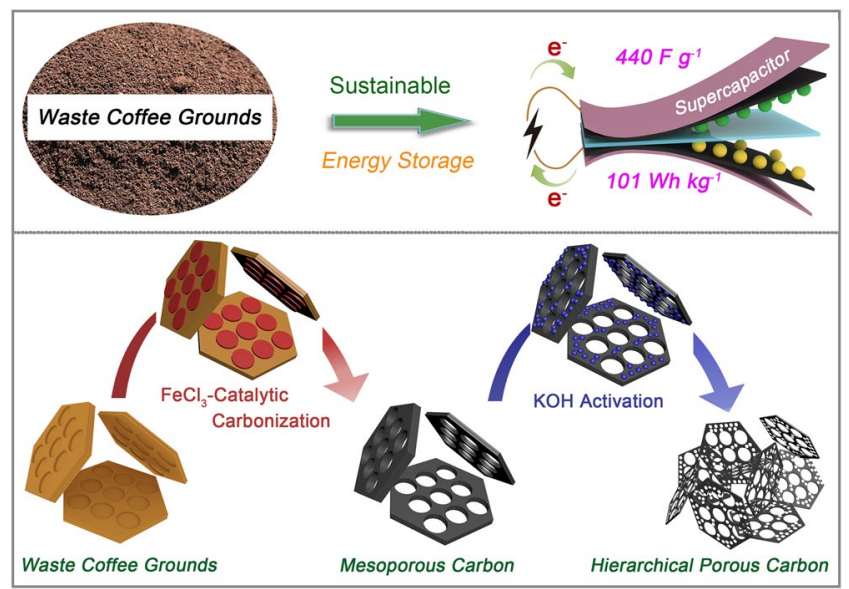

Figure 1. Synthesis process of hierarchical porous carbon from waste coffee grounds and its supercapacitor application.

where the characters of electrode materials are decisive to the resultant electrochemistry performances ${ }^{9,29}$. Among various electrode materials, porous carbons have been the most promising candidates for supercapacitor application $^{30,31}$. The ideal porous carbons should have large specific surface area for charge storage, hierarchical pores (micro-, meso- and macro-pores) for fast ion transport/diffusion and good wettability for promoting the pore access to electrolyte ions. In this case, for meeting the requirements of ideal electrode materials, it is extremely imperative to select biowastes with special structure (such as naturally porous) as carbon precursors, followed by scalable synthetic methods for achieving high carbon yield and controllable porous structure.

Coffee is one of the most widely consumed beverages and more than five million tons is produced annually. The residues of coffee grounds (CGs) are composed of cellulose, hemicellulose and lignin, which may cause environment pollution if it is not properly disposed ${ }^{32}$. Besides these common features of biomass wastes, waste CGs possess a large number of in-situ formed voids due to the dissolution of interior molecules (caffeine, tannins, polyphenols, etc.) during boiling process (Fig. S1a,b by SEM, in supporting information). These uniformly distributed voids can act as reservoirs to store catalyst, which provides the great potential for effective catalytic-carbonization. In our recent work ${ }^{33}$, waste CGs were successfully converted into functional carbon materials by one-step catalytic carbonization. Notably, the synthesized carbon possessed good graphitization degree, high surface area and mesopore-dominant structure. Considering above-mentioned characters of ideal carbons, if the porosity of waste coffee grounds is further optimized into hierarchical porous architecture, the obtained carbon will be a promising material for high-performance supercapacitive electrodes.

In the present study, a combined strategy consisting of catalytic carbonization and alkali activation was developed to convert biowastes into hierarchical porous carbon. As shown in Fig. 1, waste CGs were firstly catalyzed into mesoporous carbon by $\mathrm{FeCl}_{3}$, then the micropore-created process was performed by $\mathrm{KOH}$ activation. Furthermore, the as-prepared hierarchical porous carbon was employed as supercapacitive electrodes, which exhibited a high capacitance of $440 \mathrm{~F} \mathrm{~g}^{-1}$ at $0.5 \mathrm{Ag}^{-1}$ using $6 \mathrm{M} \mathrm{KOH}$ electrolytes in three-electrode system. The fabricated symmetric supercapacitor also displayed good rate capability $\left(81 \%\right.$ capacitance retention at $\left.20 \mathrm{Ag}^{-1}\right)$ in two-electrode system. Meanwhile, the energy density as high as $101 \mathrm{Wh} \mathrm{kg}^{-1}$ at the power density of $900 \mathrm{~W} \mathrm{~kg}^{-1}$ was demonstrated in 1-ethyl-3-methylimidazolium tetrafluoroborate $\left(\mathrm{EMIMBF}_{4}\right)$ electrolyte. We believe that it will not only open an effective route to recycle biowastes in large scale with high yield, but also develop a promising method to fabricate high-valuable carbon as electrodes for high-performance supercapacitors.

\section{Experimental Section}

Materials and preparation. Waste coffee grounds (CGs) were collected from coffee leftovers after boiling in a coffeemaker. The wet powders were dried in a vacuum oven under $80^{\circ} \mathrm{C}$ for $6 \mathrm{~h}$, and then they were crushed into tiny pieces (100 mesh). Ferric trichlorides $\left(\mathrm{FeCl}_{3}\right)$, potassium hydroxide $(\mathrm{KOH})$ and 1-Ethyl-3Methylimidazolium Tetrafluoroborate $\left(\mathrm{EMIMBF}_{4}\right)$ were purchased from Sigma-Aldrich Company, Ltd (Poland), and used directly without further purification.

Typically, CGs $(3.0 \mathrm{~g})$ was mixed with $0.6 \mathrm{~g}$ of $\mathrm{FeCl}_{3}$ in $30 \mathrm{ml}$ deionized water and sonicated for $30 \mathrm{~min}$. To achieve uniform distribution of catalyst, the slurry was frozen in a refrigerator followed by freeze-drying for $72 \mathrm{~h}$. Subsequently the fluffy sample was pyrolyzed at $700^{\circ} \mathrm{C}\left(10^{\circ} \mathrm{C} \mathrm{m^{-1 } )}\right.$ in argon for $2 \mathrm{~h}$ using a tube furnace. The resulting carbonaceous solid was hydrothermal treated by $10 \mathrm{wt} \%$ hydrochloric acid solution at $120^{\circ} \mathrm{C} \mathrm{for}$ $6 \mathrm{~h}$ and washed with distilled water, then recovered by filtration and drying (labeled as biochar). The carbon yield in carbonization process of waste coffee grounds was $42.5 \mathrm{wt} \%$, which was calculated by $\mathrm{m}_{\text {biochar }} / \mathrm{m}_{\text {waste coffee }}$ grounds $\times 100 \%$, where the $\mathrm{m}_{\text {biochar }}$ is the weight of purified biochar $(1.274 \mathrm{~g})$ and the $\mathrm{m}_{\text {waste coffee grounds }}$ is the weight of waste coffee grounds $(3.0 \mathrm{~g})$. Subsequently, part of the obtained biochar $(0.3 \mathrm{~g})$ was thoroughly mixed with different amount of $\mathrm{KOH}(0.6,1.2$, or $1.8 \mathrm{~g})$ in a mortar, then the mixture was put into a nickel crucible and heated at $800^{\circ} \mathrm{C}\left(5^{\circ} \mathrm{C} \mathrm{min}{ }^{-1}\right)$ for $2 \mathrm{~h}$ under argon in the tube furnace. After cooling to room temperature, samples were purified using $10 \mathrm{wt} \%$ hydrochloric acid solution and distilled water, and dried in an oven at $100^{\circ} \mathrm{C}$ for $12 \mathrm{~h}$. According to the mass ratio of $\mathrm{KOH} /$ biochar $=2 / 1,4 / 1$ and $6 / 1$, the obtained hierarchical porous carbons were 
named as HPC-2, HPC-4 and HPC-6. As a comparison, the biochar was also treated with the same process without additive of $\mathrm{KOH}$, and the obtained meso-/macropores dominant carbon was labeled as MC. The carbon yield was calculated by the formula: $\mathrm{m}_{\text {carbon }} / \mathrm{m}_{\text {waste coffee grounds }} \times 100 \%$, where $\mathrm{m}_{\text {carbon }}$ is the weight of purified carbon after activation process.

In addition, a control experiment from directly carbonization of waste coffee grounds and followed by $\mathrm{KOH}$ activation were conducted. In short, the waste coffee grounds were directly carbonized at $700^{\circ} \mathrm{C}\left(10^{\circ} \mathrm{C} \mathrm{min}^{-1}\right)$ for $2 \mathrm{~h}$ in argon followed by purification using $10 \mathrm{wt} \% \mathrm{HCl}$ solution and distilled water. The obtained biochar was mixed with $\mathrm{KOH}$ using mass ratio $\mathrm{m}_{\mathrm{KOH}} / \mathrm{m}_{\text {biochar }}(4: 1)$ and activated at $800^{\circ} \mathrm{C}\left(5^{\circ} \mathrm{C} \mathrm{min}{ }^{-1}\right)$ for $2 \mathrm{~h}$. After removal of impurities and drying, the product was collected and named as C-700-800.

Materials characterization. The thermal stability of samples was investigated by thermogravimetric analysis (TGA) using a TA Instruments (DTA-Q600 SDT) at a heating rate of $10^{\circ} \mathrm{C} \mathrm{min}{ }^{-1}$ from room temperature to $800^{\circ} \mathrm{C}$ under air. Field-emission scanning electron microscopy (FE-SEM, JEOLJEM-1011) at $100 \mathrm{kV}$ was applied to observe the morphology of samples. The microstructure of the samples was investigated by transmission electron microscopy (TEM) on FEI Tecnai F30 transmission electron microscope operating at an acceleration voltage of $200 \mathrm{kV}$. The vibrational properties of samples were measured by Raman scattering using a Renishaw-micro Raman spectrometer $(\lambda=532 \mathrm{~nm})$. The surface element composition of samples was characterized by means of $\mathrm{X}$-ray photoelectron spectroscopy (XPS) (VGESCALAB MKII spectrometer using an Al Ko exciting radiation from an X-ray source operated at $10.0 \mathrm{kV}$ and $10 \mathrm{~mA}$ ). The survey scanning mode was carried out to obtain the low-resolution spectra $(0-1200 \mathrm{eV})$ while the XPSPEAK 4.1 software was applied to further deconvolute the high-resolution $\mathrm{C} 1 \mathrm{~s}$ spectra $(282-292 \mathrm{eV})$ into four carbon-related Gaussian peaks. The textural properties of samples were characterized by $\mathrm{N}_{2}$ adsorption/desorption at liquid nitrogen temperature $(77 \mathrm{~K})$ using a Quantachrome Autosorb-1C-MS instrument. The multipoint-BET method (relative pressure range: $0.05<\mathrm{P} /$ $\left.\mathrm{P}_{0}<0.28\right)$ was applied to calculate the specific surface area. The total pore volume was determined at relative pressure $\mathrm{P} / \mathrm{P}_{0}=0.99$. The Nonlocal Density Functional Theory (NLDFT, slit/cylinder pores) methods were used to calculate the pore volume and pore size distribution.

Electrochemical measurements. The working electrode was prepared by firstly mixing the as-synthesized carbon materials, acetylene black and polytetrafluoroethylene (PTFE) using a mass ratio of 80/10/10 in ethanol, then the slurry was coated on a round nickel foam $(\mathrm{D}=1.0 \mathrm{~cm})$ and pressed at a pressure of $10 \mathrm{MPa}$ for $30 \mathrm{~s}$ to form working electrode followed by drying at $100^{\circ} \mathrm{C}$ for $12 \mathrm{~h}$ in an oven. The mass loading of active material was $4.0 \mathrm{mg}$ and the surface loading was $5.1 \mathrm{mg} \mathrm{cm}^{-2} .6 \mathrm{M} \mathrm{KOH}$ aqueous solution or 1-Ethyl-3-Methylimidazolium Tetrafluoroborate $\left(\mathrm{EMIMBF}_{4}\right)$ was selected as electrolytes. In three-electrode system, the $\mathrm{Hg} / \mathrm{HgO}$ electrode and Pt plate were used as reference electrode and counter electrode, respectively. In two-electrode system, the symmetrical supercapacitor was assembled using two electrodes with a glassy fiber paper as separator. The slurry of the mixture (carbon materials/acetylene black/PTFE) was pasted on the aluminum foil in electrochemical test using EMIMBF${ }_{4}$ electrolyte. The electrochemical performance was evaluated by cyclic voltammetry $(\mathrm{CV})$, galvanostatic charge/discharge (GCD) and electrochemical impedance spectroscopy (EIS) measurements using an EC-LAB VMP3 potentiostat (BioLogic Science Instruments).

In three-electrode system, the specific capacitance $\left(\mathrm{C}, \mathrm{F} \mathrm{g} \mathrm{g}^{-1}\right)$ of the electrode from $\mathrm{CV}$ curves and GCD profiles is calculated via the following equation:

$$
\begin{gathered}
C_{\text {electrode }}=\frac{1}{2 m s\left(V_{b}-V_{a}\right)} \int_{V_{a}}^{V_{b}} I d V \\
C_{\text {electrode }}=I * \Delta t /(m * \Delta V)
\end{gathered}
$$

where $I(\mathrm{~mA})$ is the current response, $V_{\mathrm{a}}$ and $V_{\mathrm{b}}$ are the upper limit and lower limit of potential, $s\left(\mathrm{mV} \mathrm{s}^{-1}\right)$ is the potential change per second, $\Delta t(\mathrm{~s})$ is the discharge time, $m(\mathrm{mg})$ is the mass loading of active material on working electrode and $\Delta V$ is the potential window $(\mathrm{V})$ for GCD test.

The diffusion coefficient of supercapacitor is calculated using EIS data according to:

$$
\begin{aligned}
& \mathrm{D}=R^{2} T^{2} / 2 A^{2} n^{4} C^{2} F^{4} \sigma^{2} \\
& Z^{\prime}=R_{c t}+R_{s}+\sigma \omega^{-1 / 2}
\end{aligned}
$$

where $\mathrm{D}, \mathrm{R}, \mathrm{T}, A, n, C, F, \sigma, Z^{\prime}, R_{c t}, R_{s}$ and $\omega$ are the diffusion coefficient, gas constant, absolute temperature, surface area, number of electrons, concentration of ions, Faraday's constant, Warburg factor, real part of impedance, charge transfer resistance, spreading resistance and frequency, respectively.

In two-electrode system, specific capacitance $\left(C, \mathrm{~F} \mathrm{~g}^{-1}\right)$ of the electrode calculated from $\mathrm{CV}$ curves and GCD profiles, energy density $\left(E, \mathrm{Wh} \mathrm{kg}^{-1}\right)$ and power density $\left(\mathrm{P}, \mathrm{W} \mathrm{kg}{ }^{-1}\right)$ of the supercapacitor derived from GCD profiles are calculated via the following equation:

$$
\begin{aligned}
& C_{\text {electrode }}=\frac{1}{m s\left(V_{b}-V_{a}\right)} \int_{V_{a}}^{V_{b}} I d V \\
& C_{\text {electrode }}=2 \times I \times \Delta t /(m \times \Delta V)
\end{aligned}
$$




$$
\begin{gathered}
E=\left(C_{\text {electrode }} \times \Delta V^{2}\right) /(8 \times 3.6) \\
P=(E \times 3600) / \Delta t
\end{gathered}
$$

where $I(\mathrm{~mA})$ is the current response, $V_{\mathrm{a}}$ and $V_{\mathrm{b}}$ are the upper limit and lower limit of voltage, $s\left(\mathrm{mV} \mathrm{s}^{-1}\right)$ is the voltage change per second, $\Delta t(\mathrm{~s})$ is the discharge time, $m(\mathrm{mg})$ is the mass loading of active material in single electrode and $\Delta V$ is the voltage change during discharge.

\section{Results and Discussion}

Carbon yields from waste CGs by catalytic carbonization and alkali activation. Our previous work has reported the catalytic carbonization of waste CGs in a crucible in a muffle furnace under air atmosphere $^{33}$. To eliminate the effect of residual oxygen in crucible and achieve the precise control of temperature, here the carbonization process was carried out in a tube furnace under argon. Similarly, $20 \mathrm{wt} \% \mathrm{FeCl}_{3}$ was added during the carbonization process of waste CGs, which leads to the carbon yield as high as $42.5 \mathrm{wt} \%$, at least ten percent higher than that of previous reports ${ }^{5,734-36}$. The high carbon yield was ascribed to the advantage of its in-situ formed voids for efficiently adsorbing $\mathrm{FeCl}_{3}$, which could form iron-containing particles under high temperature. It was reported that the iron-containing particles played a catalyst role during the carbonization process of biomass/polymer, providing a high carbon yield ${ }^{37}$. Subsequently, a $\mathrm{KOH}$ activation process (mass ratio of $\mathrm{m}_{\mathrm{KOH}} / \mathrm{m}_{\text {biochar }}=0,2,4$ or 6 ) was employed to activate carbon samples, named as MC, HPC-2, HPC-4 and HPC-6, respectively. As a result, the final carbon yields calculated from waste CGs were $41.3 \mathrm{wt} \%$ (MC), $34.5 \mathrm{wt} \%$ (HPC2), $29.5 \mathrm{wt} \%$ (HPC-4) and $22.3 \mathrm{wt} \%$ (HPC-6).

Physical characterization of waste CGs derived carbons. The morphology and microstructure of as-obtained carbons were characterized by SEM and TEM. A large amount of mesopores were homogeneously distributed on the surface of MC (Fig. 2a). Generally, the agglomeration of iron-containing particles under high temperature could act as template to form abundant mesopores in the resultant carbons. After activation, the HPC-4 possessed blanket-like rough surface, indicating the formation of abundant micropores (Fig. 2b). As shown in Fig. 2c,d, MC possesses abundant mesopores with various diameters from several nanometers to dozens nanometers. Interestingly, despite its mesoporous structure, the high-resolution TEM image of MC validates its partially graphitized structure with regular lattice fringe (green box in Fig. 2e). Fragmentized and thinner carbon sheets (Fig. 2f,g) as well as the abundant micropores (red circles in Fig. 2h) were confirmed by the TEM, revealing its amorphous character. These results demonstrated that the $\mathrm{FeCl}_{3}$ catalyst could create the mesopores-dominant structure and the subsequent $\mathrm{KOH}$ activation further introduced abundant micropores to form the hierarchical porous structure.

The graphitic nature and purity of waste CGs derived carbons were investigated by TGA under air atmosphere. As shown in Fig. 3a, the residues for all samples at $800^{\circ} \mathrm{C}$ was very close to zero, indicating that the derived products from metal catalyst and $\mathrm{KOH}$ were completely removed after purification. It is well-known that iron-containing compounds $\left(\mathrm{Fe}_{3} \mathrm{O}_{4}, \mathrm{Fe}_{3} \mathrm{C}\right.$, etc. $)$ easily grew inside carbon matrix under high temperature ${ }^{38}$, therefore hydrothermal treatment was carried out to remove iron species completely and obtain high-purified carbon. Figure $3 \mathrm{~b}$ shows DTG curves of carbon samples. With the increase of $\mathrm{KOH}$ amount, the maximum oxidation temperature $\left(T_{\max }\right)$ gradually shifted to low temperature region $\left(642.8^{\circ} \mathrm{C}\right.$ for $\mathrm{MC}$ and $552.2^{\circ} \mathrm{C}$ for $\left.\mathrm{HPC}-6\right)$, and the $T_{\max }$ peak became much broader, suggesting that the etching effect of alkali destroyed the ordered graphitized structure and introduced relatively more defects (pores, functional groups, etc.) into the carbon skeleton ${ }^{39}$. In Raman spectra (Fig. S2), the peak centered at $1352 \mathrm{~cm}^{-1}$ (D-band) was a reflection of the $\mathrm{A}_{1 \mathrm{~g}}$ vibration mode in defective carbon structure, while another peak located at $1585 \mathrm{~cm}^{-1}$ (G-band) was assigned to the stretching bond in $\mathrm{sp}^{2}$ hybridized carbon ${ }^{40}$. The intensity ratio of the $\mathrm{G}$ and $\mathrm{D}$ peak is used to evaluate the quality of obtained carbon materials ${ }^{41}$. Significantly, the integrated intensity ratio $\left(I_{\mathrm{G}} / I_{\mathrm{D}}\right)$ was determined to be $1.07,0.98,0.97$ and 0.94 for MC, HPC-2, HPC-4 and HPC-6 respectively, verifying that more defects were introduced via $\mathrm{KOH}$ treatment.

The porosity of waste CGs derived carbons was analyzed by $\mathrm{N}_{2}$ adsorption-desorption measurements. As depicted in Fig. 3c, the weaken gas adsorption within low relative pressure and a steep gas adsorption within higher relative pressure for MC belongs to typical type IV isotherms with $\mathrm{H} 3$ hysteresis, demonstrating the existence of less micropores and dominance of meso-/macropores. This result further verified the significant role of $\mathrm{FeCl}_{3}$ that mainly introduced meso-/macropores into carbon matrix during carbonization, as consistent with the TEM result. Alkali activation is widely used to produce micropores-dominant carbon with large specific surface area (SSA) and abundant micropores, as confirmed by previous reports ${ }^{42,43}$. In our work, HPCs displayed a typical I/IV pattern with a $\mathrm{H} 4$ hysteresis loop after $\mathrm{KOH}$ activation process, indicating the presence of abundant micropores and meso-/macropores. The pore size distribution of these carbons was shown in Fig. 3d, revealing that the mesopores of HPCs mainly centered at $3.5 \mathrm{~nm}$. Compared with the MC, the HPCs have more micropores (1-2 nm). Furthermore, the $S_{\text {BET }}$ increased from $801 \mathrm{~m}^{2} \mathrm{~g}^{-1}$ for MC to $3549 \mathrm{~m}^{2} \mathrm{~g}^{-1}$ for HPC-4, revealing the strong pore-making ability of $\mathrm{KOH}$. There was an anomalous reduced $\mathrm{S}_{\mathrm{BET}}$ for HPC-6, which was probably caused by the excessive $\mathrm{KOH}$ etching that resulted in the structural collapse of pores (Table 1). Among the HPCs samples, the HPC-4 possessed the highest $S_{\mathrm{BET}}\left(3549 \mathrm{~m}^{2} \mathrm{~g}^{-1}\right)$, the biggest micropore volume $\left(\mathrm{V}_{\text {micropore }}=0.64 \mathrm{~cm}^{3} \mathrm{~g}^{-1}\right)$ and wide pore size distribution with adequate mesopores $\left(\mathrm{V}_{\text {meso-/macropores }}=1.64 \mathrm{~cm}^{3} \mathrm{~g}^{-1}\right)$. These unique characters will enhance the ions storage capacity and minimize the ions diffusion limitation, thereby endows it an ideal electrode material for supercapacitor with promising electrochemical performance. As a reference, the C-700-800 exhibited a smaller $\mathrm{S}_{\mathrm{BET}}$ of $1218 \mathrm{~m}^{2} \mathrm{~g}^{-1}$ and lower meso-/macropores volume of $0.11 \mathrm{~cm}^{3} \mathrm{~g}^{-1}$ (Table $\mathrm{S} 1$ ). These results indicated that the catalytic carbonization process of $\mathrm{FeCl}_{3}$ played a significant role to create abundant meso-/macropores. 

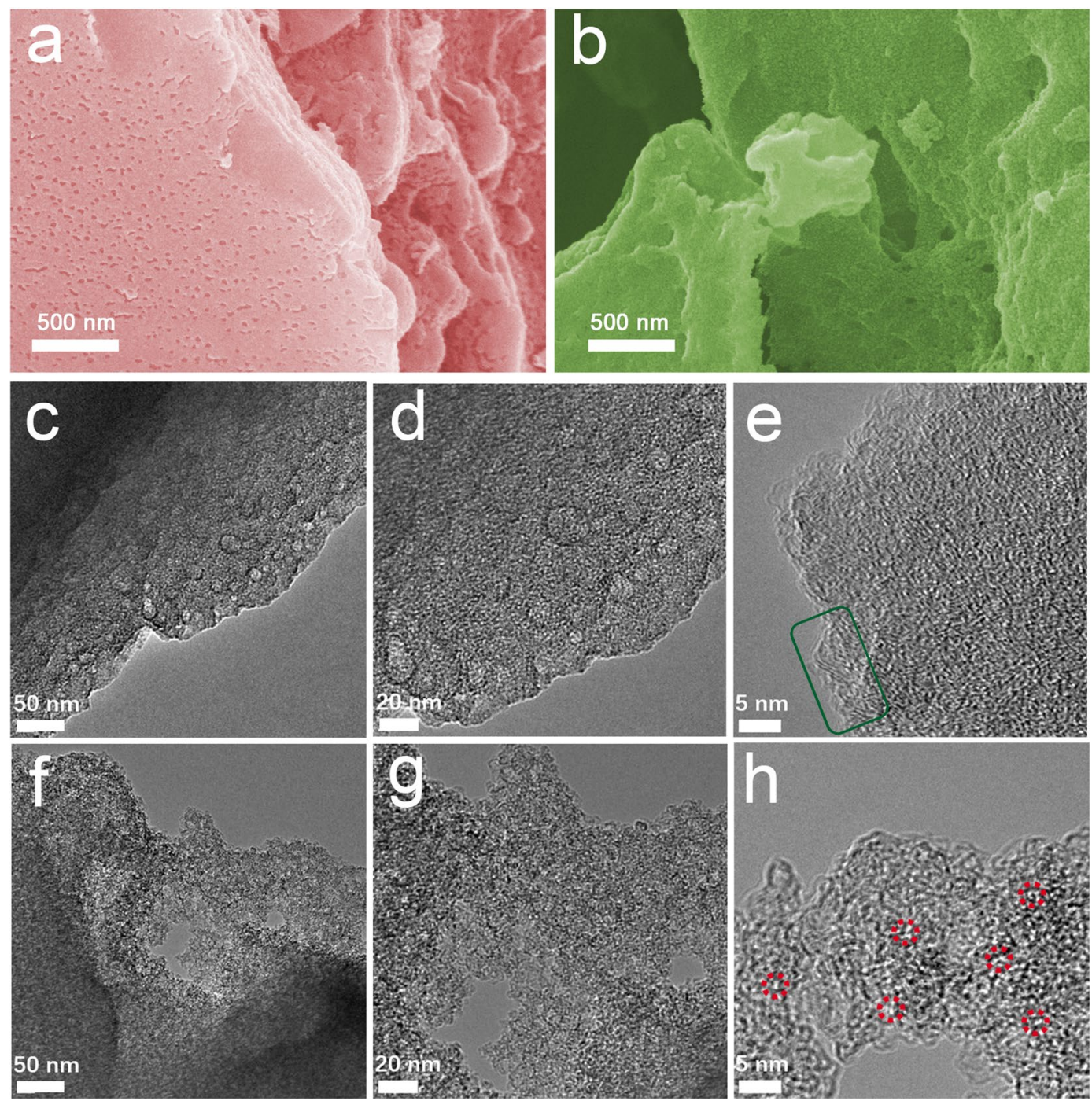

Figure 2. SEM images of waste CGs derived carbons: (a) MC and (b) HPC-4; TEM images of (c-e) MC and (f-h) HPC-4 (green box indicates the lattice fringe in MC and red circles represent the micro-pores in HPC-4).

The element composition of carbon samples was characterized by XPS. As shown in Fig. 4a,b, the survey spectra confirmed that the MC contains abundant carbon, oxygen and a little nitrogen $(1.2 \%)$. The oxygen content increases from $5.6 \%$ for MC to $11.9 \%$ for HPC-6, while the nitrogen element became undetectable for HPCs. Moreover, the high-resolution C1s XPS spectra can be fitted into four individual peaks: $\mathrm{C}-\mathrm{C}(284.6 \mathrm{eV}), \mathrm{C}-\mathrm{O}$ $(285.8 \mathrm{eV}), \mathrm{C}=\mathrm{O}(287.1 \mathrm{eV})$ and $\mathrm{O}-\mathrm{C}=\mathrm{O}(288.9 \mathrm{eV})($ Fig. $4 \mathrm{c}-\mathrm{f})$. It is clearly observed that the $\mathrm{C}-\mathrm{O}$ and $\mathrm{O}-$ $\mathrm{C}=\mathrm{O}$ content significantly increased during activation process (The detailed data were summarized in Table S2 in supporting information). It was reported that the incorporation of oxygen-containing groups into the carbon matrix could not only effectively enhance the capacitance by providing the pseudocapacitance, but also improve the wettability of fabricated electrode ${ }^{44}$. Therefore, the abundant oxygen-containing groups in our carbon materials may play an important role in their electrochemical performance.

Electrochemical performance evolution in three-electrode system. The electrochemical properties of coffee grounds derived carbons were analyzed in a three-electrode configuration using $6.0 \mathrm{M} \mathrm{KOH}$ electrolyte. Figure 5a shows the $\mathrm{CV}$ curves at a scan rate of $20 \mathrm{mV} \mathrm{s}^{-1}$ with the potential range of $-1 \mathrm{~V}$ to $0 \mathrm{~V}$. It was apparent that the CV curve of HPC-4 displayed a quasi-rectangular shape without redox peaks, indicating the dominance of electric double-layer capacitive (EDLC) behavior during the charge-discharge process. Meanwhile, the highest discharge current and the biggest integral area of HPC-4 suggested its highest specific capacitance. The rectangular shape maintained even at a high scan rate of $200 \mathrm{mV} \mathrm{s}^{-1}$ (Fig. S3), revealing the important role of sufficient meso-/macropores in the carbon structure that mitigates the ions diffusion limitation. The maximum capacitance was $466 \mathrm{Fg}^{-1}$ at $1 \mathrm{mV} \mathrm{s}^{-1}$ and it dropped to $324 \mathrm{Fg}^{-1}$ at $200 \mathrm{mV} \mathrm{s}^{-1}$ (Fig. S4). As shown in Fig. 5b, the GCD profiles at $2 \mathrm{Ag}^{-1}$ displayed well-defined triangular shapes, which is indicative of typical capacitor behavior.

The calculated specific capacitances based on the discharge profiles at $0.5 \mathrm{~A} \mathrm{~g}^{-1}$ were $185,393,440$ and $350 \mathrm{Fg}^{-1}$ for MC, HPC-2, HPC-4 and HPC-6, respectively. Notably, herein the capacitance of HPC- 4 was much higher than $123 \mathrm{~F} \mathrm{~g}^{-1}$ of commercial activated carbon (YP-50F, Kuraray) tested under same condition (Fig. S5), 
a
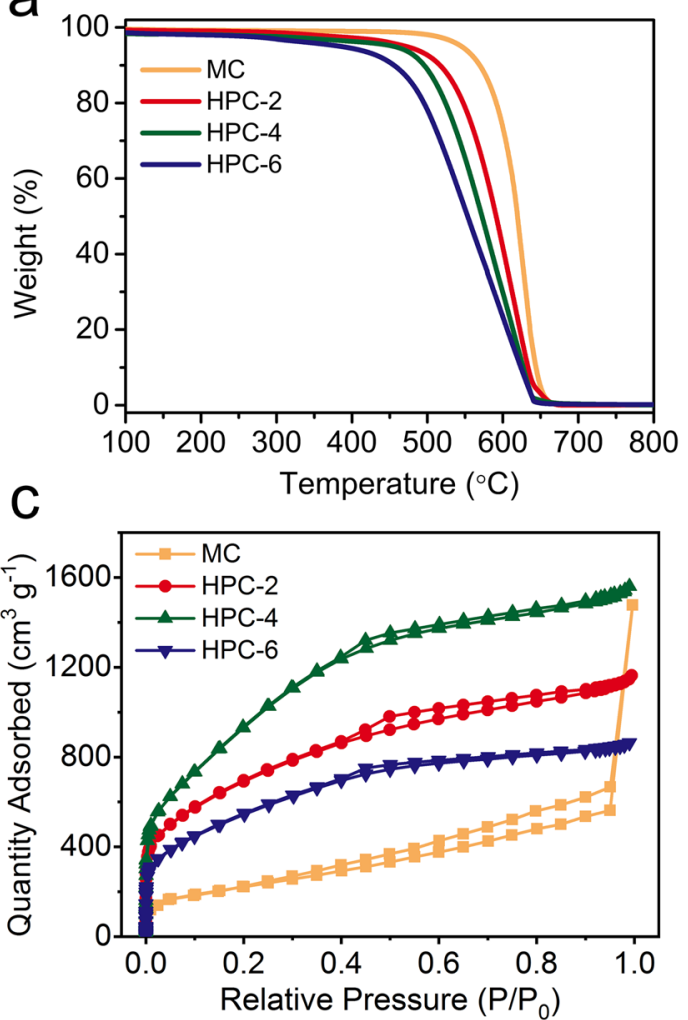

b
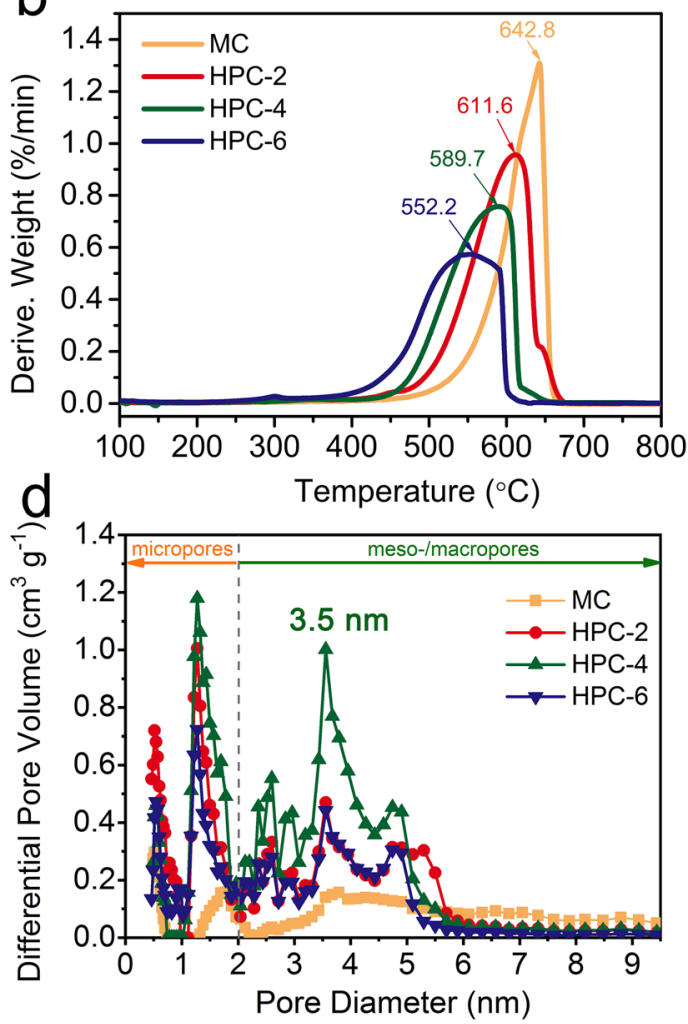

Figure 3. (a) TGA, (b) DTG curves, (c) Nitrogen adsorption/desorption isotherms and (d) pore size distribution of waste CGs derived carbons calculated by NLDFT method.

\begin{tabular}{|l|l|l|l|l|l|}
\hline Samples & $\begin{array}{l}\mathrm{S}_{\mathrm{BET}} \\
\left(\mathbf{m}^{\mathbf{2}} \mathbf{g}^{-\mathbf{1}}\right)\end{array}$ & $\begin{array}{l}\mathbf{V}_{\mathbf{t}} \\
\left(\mathbf{c m}^{3} \mathbf{g}^{-1}\right)\end{array}$ & $\begin{array}{l}\mathbf{V}_{\mathrm{t}-\mathrm{DFT}} \\
\left(\mathbf{c m}^{\mathbf{3}} \mathbf{g}^{-\mathbf{1}}\right)\end{array}$ & $\begin{array}{l}\mathbf{V}_{\text {micropores-DFT }} \\
\left(\mathbf{c m}^{\mathbf{3}} \mathbf{g}^{-1}\right)\end{array}$ & $\begin{array}{l}\mathbf{V}_{\text {meso/macropores-DFT }} \\
\left(\mathbf{c m}^{\mathbf{3}} \mathbf{g}^{-1}\right)\end{array}$ \\
\hline MC & 801 & $1.03^{\mathrm{a}}$ & 1.01 & 0.11 & 0.90 \\
\hline HPC-2 & 2513 & 1.80 & 1.69 & 0.58 & 1.11 \\
\hline HPC-4 & 3549 & 2.41 & 2.28 & 0.64 & 1.64 \\
\hline HPC-6 & 1999 & 1.34 & 1.27 & 0.42 & 0.85 \\
\hline
\end{tabular}

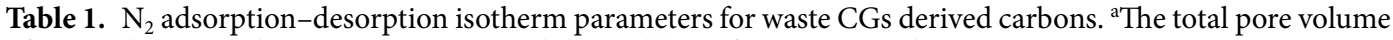
of $\mathrm{MC}$ is determined at $\mathrm{P} / \mathrm{P}_{0}=0.95$ to avoid the problem of nitrogen condensation.

and it was also superior to many other previously reported biomass-derived carbons (Table 2). In general, high-rate charge-discharge process usually results in the deterioration in charge storage capacity because of limited time for electrolyte ions diffusion within the whole electrode ${ }^{45}$. But in our work, with increasing the current density up to $10 \mathrm{Ag}^{-1}$, a high capacitance of $313 \mathrm{~F} \mathrm{~g}^{-1}$ was obtained (Fig. 5c). Even at a high current density of $20 \mathrm{Ag}^{-1}$, a superior rate capability $\left(293 \mathrm{Fg}^{-1}, 67 \%\right.$ capacitance retention) is obtained, implying the fast ion diffusion rate. In addition, the reference sample (C-700-800) with less meso-/macropores exhibited a capacitance of $241 \mathrm{Fg}^{-1}$ at $0.5 \mathrm{Ag}^{-1}$ (Fig. S6a), and this value quickly dropped to $128 \mathrm{Fg}^{-1}$ at $20 \mathrm{Ag}^{-1}$, so its capacitance retention was only $53 \%$ (Fig. S6b). These results revealed the important role of sufficient meso-/macropores in fast ions transport for enhanced rate capability.

Electrochemical impedance spectroscopy (EIS) measurement in the frequency range of $100 \mathrm{kHz}$ to 10 $\mathrm{mHz}$ was applied to investigate the different ion transport/charge transfer properties. The Nyquist plots featured the semicircle in the high-frequency region followed by the 45 Warburg-type line and straight line in the low-frequency region, suggesting the combination of charge transfer and ion transport behavior in supercapacitor (Fig. 5d). In the high-frequency region, the smallest diameter of semicircle for HPC-4 marked its lowest $\mathrm{R}_{\mathrm{ct}}$ with a fast charge transfer rate. Furthermore, the equivalent circuit model was employed to evaluate the $R_{c t}$ values of fabricated supercapacitors, which was entirely consistent with Nyquist data to confirm the lowest $\mathrm{R}_{\mathrm{ct}}(0.53 \Omega)$ of HPC-4 (Fig. S7). In the low-frequency region, the straight line of HPC-4 was almost parallel to - $Z^{\prime \prime}$ axis, revealing its typical double-layer capacitive behavior without ion diffusion limitation. Moreover, the diffusion coefficient (D, calculated from Eqs. (3) and (4) in electrochemical measurements part) was used to quantitatively compare the ion diffusion behavior in supercapacitors. As a key parameter reflecting the ion diffusion impedance, the Warburg factor $(\sigma)$ can be obtained from the relationship between $Z^{\prime}$ and $\omega^{-1 / 2}$ (Fig. 5e). The plots displayed 

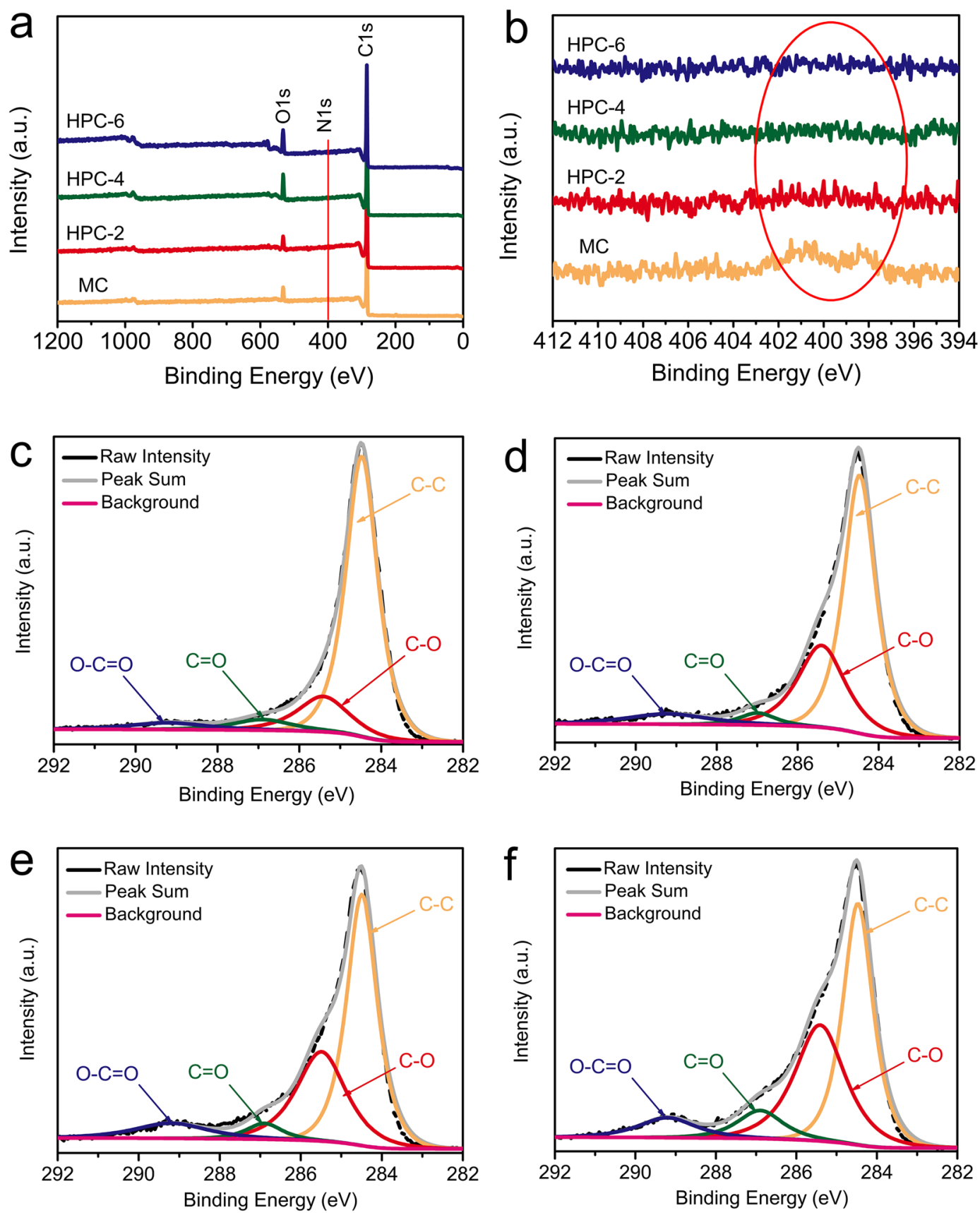

Figure 4. (a)XPS survey and (b) N1s spectra of samples; high-resolution spectra of C1s for (c) MC, (d) HPC-2, (e) HPC-4 and (f) HPC-6.

linear features with different slopes $(\sigma)$ of $1.43,0.30,0.29$ and 0.11 for MC, HPC-2, HPC-4 and HPC-6, respectively. As a result, the calculated diffusion coefficient (D) for HPC-4 was about 24 times higher than that of MC.

By extrapolating the vertical part of the plot to the real axis, the obtained intercept was named as equivalent series resistance $\left(\mathrm{R}_{\mathrm{ESR}}\right)$, which represents the combination of ohmic resistance of electrolyte, electrical resistance of electrode and ionic diffusion resistance in the electrode ${ }^{46}$. A low $\mathrm{R}_{\mathrm{ESR}}$ of $1.03 \Omega$ was obtained for HPC-4 (Fig. S8). Furthermore, the Bode plots showed that the phase angles of all samples were close to $-90^{\circ}$ at $0.01 \mathrm{~Hz}$, suggesting their ideal capacitive behavior (Fig. $5 f$ ). The characteristic frequency $\left(f_{0}\right)$ at $-45^{\circ}$ marks the point at which the capacitive impedance equals to resistive impedance. The $\mathrm{f}_{0}$ was $0.32 \mathrm{~Hz}, 0.53 \mathrm{~Hz}, 0.59 \mathrm{~Hz}$ and $0.53 \mathrm{~Hz}$ for MC, HPC-2, HPC- 4 and HPC-6, respectively. The derived time constant $t_{0}\left(t_{0}=1 / f_{0}\right)$ was calculated to be as short as $1.68 \mathrm{~s}$ for HPC-4, much shorter than $10 \mathrm{~s}$ of commercial activated carbon-based supercapacitors. The rapid frequency response of HPC-4 further confirmed its better ion transport behavior that relied on the large ion-accessible SSA and the hierarchical porous structure. 

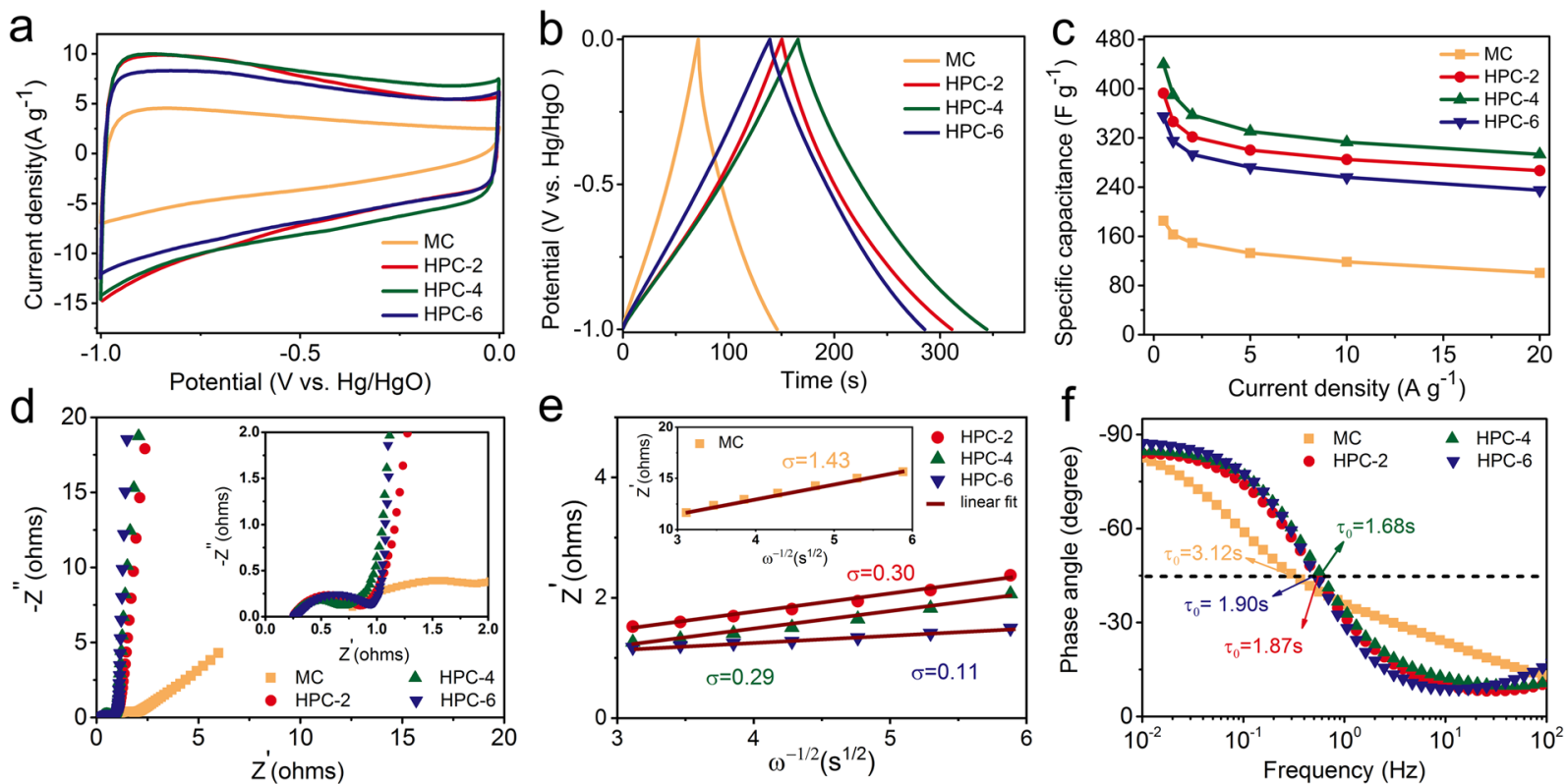

Figure 5. Electrochemical performance of waste CGs derived carbons in a three-electrode system using $6 \mathrm{M}$ KOH electrolyte: (a) CV curves at $20 \mathrm{mV} \mathrm{s}^{-1}$; (b) GCD profiles at $2 \mathrm{Ag}^{-1}$; (c) Comparison of the capacitance at different current densities; (d) Nyquist plots; (e) A plot of real impedance as a function of $\omega^{-1 / 2}$ and (f) Bode phase plots.

\begin{tabular}{|c|c|c|c|c|c|c|}
\hline Biomass & $\begin{array}{l}\text { Test system } \\
\text { (electrode) }^{a} / \\
\text { Electrolyte }\end{array}$ & $\begin{array}{l}\text { Current } \\
\text { density } \\
\left(\mathrm{A} \mathrm{g}^{-1}\right) \\
\end{array}$ & \begin{tabular}{|l|} 
Specific \\
capacitance \\
$\left(\mathrm{Fg}^{-1}\right)$ \\
\end{tabular} & \begin{tabular}{|l|l}
$\begin{array}{l}\text { Energy } \\
\text { density } \\
\left(\mathrm{Wh} \mathrm{kg}^{-1}\right)\end{array}$ \\
\end{tabular} & \begin{tabular}{|l|}
$\begin{array}{l}\text { Power } \\
\text { density } \\
\left(\mathrm{W} \mathrm{kg}^{-1}\right)\end{array}$ \\
\end{tabular} & Ref. \\
\hline \multirow[t]{2}{*}{ Bagasse } & $3 \mathrm{E} / 6 \mathrm{M} \mathrm{KOH}$ & 0.5 & 320 & - & - & 24 \\
\hline & $2 \mathrm{E} / 6 \mathrm{M} \mathrm{KOH}$ & 0.2 & 180 & 6.3 & 100 & \\
\hline \multirow[t]{2}{*}{ Cashmere } & $3 \mathrm{E} / 6 \mathrm{M} \mathrm{KOH}$ & 0.5 & 363 & - & - & 48 \\
\hline & $2 \mathrm{E} / \mathrm{TEABF}_{4}$ & 0.5 & 81 & 18 & 125 & \\
\hline Fungus & $3 \mathrm{E} / 6 \mathrm{M} \mathrm{KOH}$ & 0.5 & 374 & - & - & 49 \\
\hline Silk & $2 \mathrm{E} / \mathrm{EMIMBF}_{4}$ & 1 & 213 & 90 & 875 & 50 \\
\hline Tofu & 3E/6 M KOH & 1 & 418 & - & - & 10 \\
\hline Artemia shells & $3 \mathrm{E} / 6 \mathrm{M} \mathrm{KOH}$ & 0.5 & 426 & - & - & 51 \\
\hline \multirow[t]{3}{*}{ Mushroom } & $3 \mathrm{E} / 6 \mathrm{M} \mathrm{KOH}$ & 1 & 306 & - & - & 52 \\
\hline & $2 \mathrm{E} / 6 \mathrm{M} \mathrm{KOH}$ & 0.2 & 238 & 8.2 & 100 & \\
\hline & $2 \mathrm{E} / \mathrm{TEABF}_{4}$ & 0.5 & 149 & 31.7 & 620 & \\
\hline Protein & $3 \mathrm{E} / 1 \mathrm{M} \mathrm{H}_{2} \mathrm{SO}_{4}$ & 0.2 & 390 & - & - & 53 \\
\hline Seed dregs & $3 \mathrm{E} / 6 \mathrm{M} \mathrm{KOH}$ & 1 & 333 & - & - & 54 \\
\hline Cinnamon & $2 \mathrm{E} / \mathrm{NaClO}_{4}$ & 0.5 & 225 & 70 & 375 & 55 \\
\hline Cherry calyces & $2 \mathrm{E} / \mathrm{EMIMBF}_{4}$ & 1 & 173 & 81.4 & 446.3 & 56 \\
\hline Coconut shell & $2 \mathrm{E} / 6 \mathrm{M} \mathrm{KOH}$ & 1 & 276 & 9.6 & 500 & 57 \\
\hline Lignin & $2 \mathrm{E} / \mathrm{EMIMBF}_{4}$ & 0.1 & 192 & 64.2 & 74.5 & 58 \\
\hline Albizzia flower & 3E/6 M KOH & 0.5 & 406 & - & - & 59 \\
\hline \multirow[t]{3}{*}{ Coffee grounds } & $3 \mathrm{E} / 6 \mathrm{M} \mathrm{KOH}$ & 0.5 & 440 & - & - & \begin{tabular}{|l|} 
This work \\
\end{tabular} \\
\hline & $2 \mathrm{E} / 6 \mathrm{M} \mathrm{KOH}$ & 0.5 & 319 & 11.1 & 125 & \\
\hline & $2 \mathrm{E} / \mathrm{EMIMBF}_{4}$ & 1 & 224 & 101 & 900 & \\
\hline
\end{tabular}

Table 2. Comparison of the electrochemical capacitance of biomass-derived carbon-based electrode in aqueous and organic electrolyte. ${ }^{2} 2 \mathrm{E} / 3 \mathrm{E}$ indicates a two-electrode/three-electrode system.

Electrochemical performance evolution in two-electrode system. To evaluate its practical application in energy storage, HPC-4 was assembled in a two-electrode symmetric supercapacitor using $6 \mathrm{M}$ $\mathrm{KOH}$ electrolyte. The rectangular shape of $\mathrm{CV}$ curves maintained at a scan rate as high as $200 \mathrm{mV} \mathrm{s}^{-1}$, indicating the key role of hierarchical pores that facilitated fast ions transport throughout the entire electrode during short time (Fig. S9a). The GCD profiles exhibited the well-defined triangle shape at various current densities (Fig. S9b). The specific capacitance was $319 \mathrm{Fg}^{-1}$ at $0.5 \mathrm{Ag}^{-1}$ for HPC-4 based electrode. Furthermore, at a high 

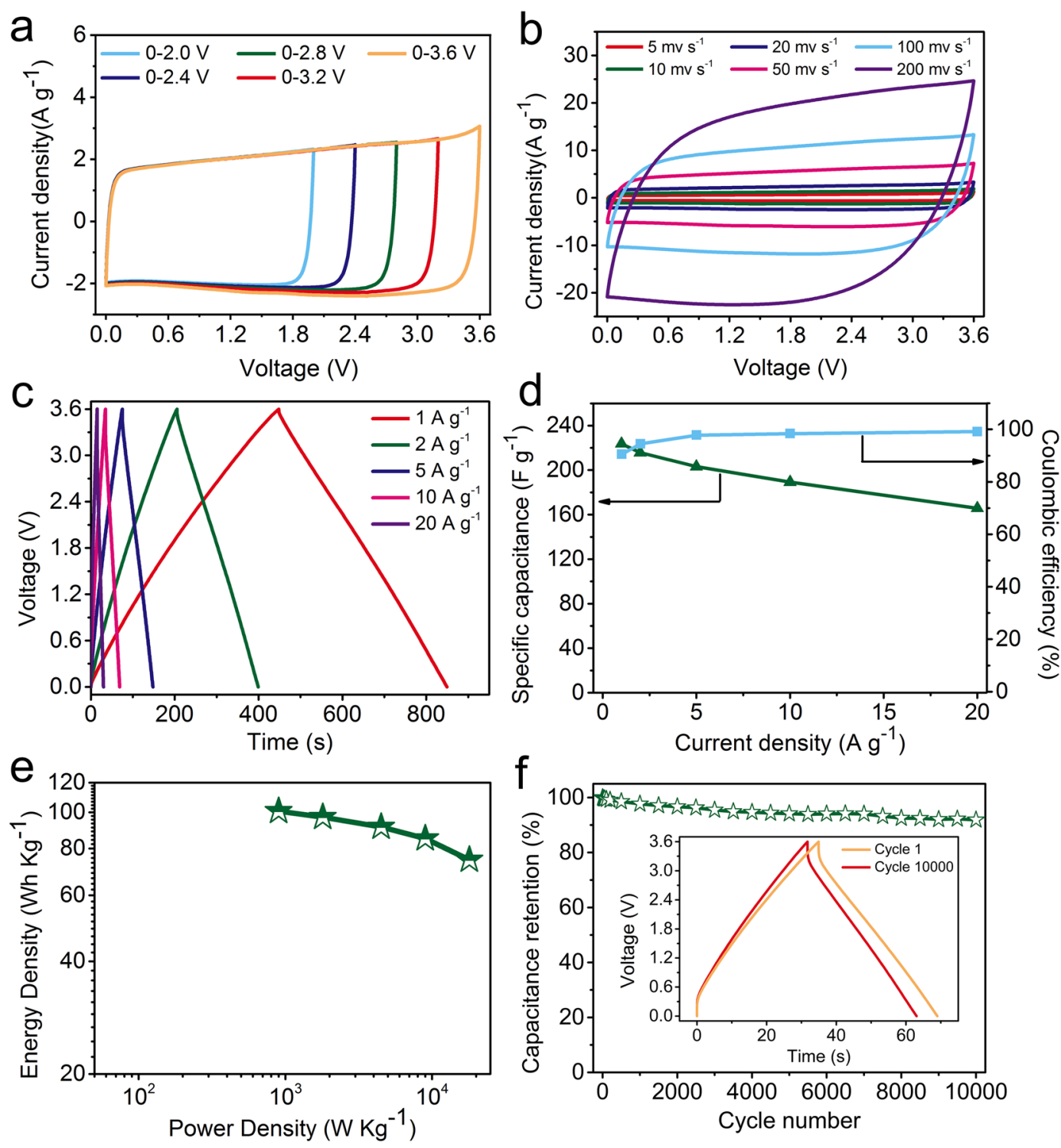

Figure 6. Electrochemical performance of $\mathrm{HPC}-4$ in neat $\mathrm{EMIMBF}_{4}$ : (a) $\mathrm{CV}$ curves at $20 \mathrm{mV} \mathrm{s}^{-1}$ at different operation voltages; (b) CV curves from 5 to $200 \mathrm{mV} \mathrm{s}^{-1}$; (c) GCD profiles from 1 to $20 \mathrm{~A} \mathrm{~g}^{-1}$; (d) Capacitance and coulombic efficiency as a function of the current density; (e) Ragone plot; (f) Cycle stability of HPC-4 at $10 \mathrm{Ag}^{-1}$.

current density of $20 \mathrm{Ag}^{-1}$, a high capacitance of $259 \mathrm{Fg}^{-1}$ was still remained with a good rate capability of $81 \%$ (Fig. S9c). Meanwhile, a high coulombic efficiency (>96\%) was achieved. In addition, the long cycle test exhibited $94 \%$ capacitance retention after 10000 cycles at a current density of $10 \mathrm{Ag}^{-1}$ for HPC-4 based supercapacitor (Fig. S9d). The Nyquist plots shifted to right position after long cycling test, indicating the slightly increased equivalent series resistance.

The electrochemical properties of HPC-4 were further investigated in ionic liquid due to its wide electrochemical window as compared to aqueous electrolytes. Two symmetric electrodes were assembled in coin-type cell using neat $\mathrm{EMIMBF}_{4}$ electrolyte. Initially the $\mathrm{CV}$ measurement at a scan rate of $20 \mathrm{mV} \mathrm{s}^{-1}$ was carried out in voltage ranging from $0-2.0 \mathrm{~V}$ to $0-3.6 \mathrm{~V}$ to test the stability of fabricated device using neat $\mathrm{EMIMBF}_{4}$ (Fig. 6a). Previous work has revealed that the neat $\mathrm{EMIMBF}_{4}$ can be operated under the voltage window from 0-3 V to 0-4 V without decomposition $^{44,47}$. At $0-3.6 \mathrm{~V}$, our fabricated device exhibited the rectangular CV curve without apparent increase of anodic current, indicating its good EDLC behavior and superior reversibility. Therefore, the electrochemical performance was further studied based on CV curves and GCD profiles within a voltage window of $0-3.6 \mathrm{~V}$.

Similar to the behavior in $6 \mathrm{M} \mathrm{KOH}$ electrolyte, even at a high scan rate of $200 \mathrm{mV} \mathrm{s}^{-1}$, CV curve still maintained a quasi-rectangular shape (Fig. 6b). The maximum capacitance of HPC-4 based electrode calculated from $\mathrm{CV}$ curves is $254 \mathrm{Fg}^{-1}$ at $5 \mathrm{mV} \mathrm{s}^{-1}$ (Fig. S10). Meanwhile, HPC- 4 exhibited a symmetric triangular shape at different current densities from 1 to $20 \mathrm{Ag}^{-1}$ (Fig. 6c). The calculated specific capacitance of HPC-4 based electrode was $224 \mathrm{Fg}^{-1}$ at $1 \mathrm{~A} \mathrm{~g}^{-1}$, which was much better than that of most biomass-derived porous carbons (Table 2). 
Increasing the current density up to $20 \mathrm{Ag}^{-1}$, the high capacitance of $166 \mathrm{Fg}^{-1}$ was still present (Fig. $6 \mathrm{~d}$ ). It was believed that the high capacitance and good rate capability were ascribed to the abundant meso-/macropores that guarantees rapid diffusion of larger $\mathrm{EMIM}^{+}$ions to access the inner surfaces. Meanwhile, the device showed a high coulombic efficiency of $91 \%$ at $1 \mathrm{Ag}^{-1}$. Moreover, the obtained Nyquist plot showed a straight line parallel to $-Z^{\prime \prime}$ axis, which indicates the good electrolyte ions transport/charge transfer capacity (Fig. S11). In addition, the specific energy density (E, Wh kg-1) and power density $\left(\mathrm{P}, \mathrm{W} \mathrm{kg}{ }^{-1}\right)$ of HPC-4 based supercapacitor was calculated based on Eqs. (7) and (8). As our expected, the HPC-4 exhibited a high energy density of $101 \mathrm{Wh} \mathrm{kg}^{-1}$ at power density of $900 \mathrm{~W} \mathrm{~kg}^{-1}$, and still remained $75 \mathrm{Wh} \mathrm{kg}^{-1}$ at a power density of $18 \mathrm{~kW} \mathrm{~kg}^{-1}$ (Fig. 6e). These values were at least comparable or higher than that of most other biomass derived carbon materials (Table 2). Besides, long cycle test demonstrated good stability with high capacitance retention of $92 \%$ over the 10000 charge-discharge cycles at a current density of $10 \mathrm{Ag}^{-1}$ (Fig. 6f).

\section{Conclusions}

In summary, we developed a cost-effective combined strategy to fabricate hierarchical porous carbon from waste coffee grounds by catalytic carbonization and alkali activation, and explored it application for high performance supercapacitive electrodes. A well-defined mesoporous carbon was obtained with a high carbon yield of $42.5 \mathrm{wt} \%$ via catalytic carbonization process, while subsequent activation process produced hierarchical porous carbon, which consisted of 3D porous architecture with ultrahigh surface area $\left(3549 \mathrm{~m}^{2} \mathrm{~g}^{-1}\right)$ and large meso-/macropores volume of $1.64 \mathrm{~cm}^{3} \mathrm{~g}^{-1}$. These advantageous features were beneficial to maximize charge storage capacity and fast ions diffusion/transport rate. In three-electrode system, the HPC-4 based electrodes displayed high specific capacitance $\left(440 \mathrm{Fg}^{-1}\right.$ at $\left.0.5 \mathrm{Ag}^{-1}\right)$ in $6 \mathrm{M} \mathrm{KOH}$ aqueous electrolyte. In two-electrode system, the fabricated symmetric supercapacitor exhibited an outstanding rate capability ( $81 \%$ capacitance retention at $\left.20 \mathrm{Ag}^{-1}\right)$. Moreover, a maximum energy density of $101 \mathrm{Wh} \mathrm{kg}^{-1}$ was achieved at a power density of $900 \mathrm{~W} \mathrm{~kg}^{-1}$ in $\mathrm{EMIMBF}_{4}$ electrolyte, which was comparable or much higher than that of most other biomass derived carbon materials. We believe that this combined strategy will be applicable to recycle not only waste coffee grounds, but also other biowaste resources. It will open a door for fabricating promising carbon materials and developing more exciting applications in the field of energy storage.

Received: 28 October 2019; Accepted: 12 February 2020; Published online: 26 February 2020

\section{References}

1. Purkait, T., Singh, G., Singh, M., Kumar, D. \& Dey, R. S. Large area few-layer graphene with scalable preparation from waste biomass for high-performance supercapacitor. Sci. Rep.-Uk 7, https://doi.org/10.1038/s41598-017-15463-w (2017).

2. Fic, K., Platek, A., Piwek, J. \& Frackowiak, E. Sustainable materials for electrochemical capacitors. Mater. Today 21, 437-454, https:// doi.org/10.1016/j.mattod.2018.03.005 (2018).

3. Xu, D., Tong, Y., Yan, T. T., Shi, L. Y. \& Zhang, D. S. N. P-Codoped Meso-/Microporous Carbon Derived from Biomass Materials via a Dual-Activation Strategy as High-Performance Electrodes for Deionization Capacitors. ACS Sustain. Chem. Eng. 5, 5810-5819, https://doi.org/10.1021/acssuschemeng.7b00551 (2017).

4. Razmjooei, F. et al. Urine to highly porous heteroatom-doped carbons for supercapacitor: A value added journey for human waste. Sci. Rep.-Uk 7, 14, https://doi.org/10.1038/s41598-017-11229-6 (2017).

5. Cantrell, K. B., Hunt, P. G., Uchimiya, M., Novak, J. M. \& Ro, K. S. Impact of pyrolysis temperature and manure source on physicochemical characteristics of biochar. Bioresour. Technol. 107, 419-428, https://doi.org/10.1016/j.biortech.2011.11.084 (2012).

6. Chen, B. L., Zhou, D. D. \& Zhu, L. Z. Transitional adsorption and partition of nonpolar and polar aromatic contaminants by biochars of pine needles with different pyrolytic temperatures. Env. Sci. Technol. 42, 5137-5143, https://doi.org/10.1021/es8002684 (2008).

7. Ahmad, M. et al. Effects of pyrolysis temperature on soybean stover- and peanut shell-derived biochar properties and TCE adsorption in water. Bioresour. Technol. 118, 536-544, https://doi.org/10.1016/j.biortech.2012.05.042 (2012).

8. Preuss, K., Tanase, L. C., Teodorescu, C. M., Abrahams, I. \& Titirici, M. M. Sustainable metal-free carbogels as oxygen reduction electrocatalysts. J. Mater. Chem. A 5, 16336-16343, https://doi.org/10.1039/c7ta02001e (2017).

9. Min, J. K. et al. From polystyrene waste to porous carbon flake and potential application in supercapacitor. Waste Manage. 85, 333-340, https://doi.org/10.1016/j.wasman.2019.01.002 (2019).

10. Ouyang, T. et al. Molten salt synthesis of nitrogen doped porous carbon: a new preparation methodology for high-volumetric capacitance electrode materials. J. Mater. Chem. A 4, 9832-9843, https://doi.org/10.1039/c6ta02673g (2016).

11. Zhang, H., Zhou, X. L., Shao, L. M., Lu, F. \& He, P. J. Hierarchical Porous Carbon Spheres from Low-Density Polyethylene for HighPerformance Supercapacitors. Acs Sustain. Chem. Eng. 7, 3801-3810, https://doi.org/10.1021/acssuschemeng.8b04539 (2019).

12. Lu, H. Y. et al. Nitrogen-Doped Carbon Polyhedra Nanopapers: An Advanced Binder-Free Electrode for High-Performance Supercapacitors. Acs Sustain. Chem. Eng. 7, 5240-5248, https://doi.org/10.1021/acssuschemeng.8b06159 (2019).

13. Zhu, J. B. et al. Highly polarized carbon nano-architecture as robust metal-free catalyst for oxygen reduction in polymer electrolyte membrane fuel cells. Nano Energy 49, 23-30, https://doi.org/10.1016/j.nanoen.2018.04.021 (2018).

14. Zhao, L. et al. Nitrogen-Containing Hydrothermal Carbons with Superior Performance in Supercapacitors. Adv. Mater. 22, 5202, https://doi.org/10.1002/adma.201002647 (2010).

15. Liu, B. et al. Graphene-like porous carbon nanosheets derived from salvia splendens for high-rate performance supercapacitors. J. Power Sources 397, 1-10, https://doi.org/10.1016/j.jpowsour.2018.06.100 (2018).

16. Wang, C. J. et al. Nitrogen-doped two-dimensional porous carbon sheets derived from clover biomass for high performance supercapacitors. J. Power Sources 363, 375-383, https://doi.org/10.1016/j.jpowsour.2017.07.097 (2017).

17. Cai, Y. J. et al. Facile Synthesis of Three-Dimensional Heteroatom-Doped and Hierarchical Egg-Box-Like Carbons Derived from Moringa oleifera Branches for High-Performance Supercapacitors. ACS Appl. Mater. Interfaces 8, 33060-33071, https://doi. org/10.1021/acsami.6b10893 (2016).

18. Shao, J. Q. et al. In-situ MgO (CaCO3) templating coupled with $\mathrm{KOH}$ activation strategy for high yield preparation of various porous carbons as supercapacitor electrode materials. Chem. Eng. J. 321, 301-313, https://doi.org/10.1016/j.cej.2017.03.092 (2017).

19. Zhang, L. et al. High-Performance Supercapacitor Electrode Materials Prepared from Various Pollens. Small 9, 1342-1347, https:// doi.org/10.1002/smll.201202943 (2013).

20. Chen, W. M., Wang, X., Luo, M., Yang, P. \& Zhou, X. Y. Fast one-pot microwave preparation and plasma modification of porous carbon from waste lignin for energy storage application. Waste Manage 89, 129-140, https://doi.org/10.1016/j.wasman.2019.03.056 (2019).

21. Schlee, P. et al. Free-standing supercapacitors from Kraft lignin nanofibers with remarkable volumetric energy density. Chem. Sci. 10, 2980-2988, https://doi.org/10.1039/c8sc04936j (2019). 
22. Ferrero, G. A., Fuertes, A. B. \& Sevilla, M. From Soybean residue to advanced supercapacitors. Sci Rep-Uk 5, https://doi.org/10.1038/ srep16618 (2015)

23. Shen, F., Su, J. L., Zhu, L. F., Qi, X. H. \& Zhang, X. Comprehensive utilization of dairy manure to produce glucose and hierarchical porous carbon for supercapacitors. Cellulose 24, 2571-2579, https://doi.org/10.1007/s10570-017-1267-0 (2017).

24. Feng, H. B. et al. Hierarchical structured carbon derived from bagasse wastes: A simple and efficient synthesis route and its improved electrochemical properties for high-performance supercapacitors. J. Power Sources 302, 164-173, https://doi.org/10.1016/j. jpowsour.2015.10.063 (2016).

25. Thue, P. S. et al. Effects of first-row transition metals and impregnation ratios on the physicochemical properties of microwaveassisted activated carbons from wood biomass. J. Colloid Interf. Sci. 486, 163-175, https://doi.org/10.1016/j.jcis.2016.09.070 (2017).

26. Simon, P. \& Gogotsi, Y. Materials for electrochemical capacitors. Nat. Mater. 7, 845-854, https://doi.org/10.1038/nmat2297 (2008).

27. Slesinski, A., Matei-Ghimbeu, C., Fic, K., Beguin, F. \& Frackowiak, E. Self-buffered pH at carbon surfaces in aqueous supercapacitors. Carbon 129, 758-765, https://doi.org/10.1016/j.carbon.2017.12.101 (2018).

28. Tian, J., Shi, Y. Q., Fan, W. \& Liu, T. X. Ditungsten carbide nanoparticles embedded in electrospun carbon nanofiber membranes as flexible and high-performance supercapacitor electrodes. Compos. Commun. 12, 21-25, https://doi.org/10.1016/j.coco.2018.12.003 (2019).

29. Song, Z. Y. et al. High-energy flexible solid-state supercapacitors based on O, N, S-tridoped carbon electrodes and a $3.5 \mathrm{~V}$ gel-type electrolyte. Chem. Eng. J. 372, 1216-1225, https://doi.org/10.1016/j.cej.2019.05.019 (2019).

30. Gorska, B., Frackowiak, E. \& Beguin, F. Redox active electrolytes in carbon/carbon electrochemical capacitors. Curr. Opin. Electroche 9, 95-105, https://doi.org/10.1016/j.coelec.2018.05.006 (2018).

31. Zhu, D. Z. et al. A general strategy to synthesize high-level N-doped porous carbons via Schiff-base chemistry for supercapacitors. J. Mater. Chem. A 6, 12334-12343, https://doi.org/10.1039/c8ta02341g (2018).

32. Roussos, S. et al. Biotechnological Management Of Coffee Pulp - Isolation, Screening Characterization, Selection of Caffeine Degrading Fungi And Natural Microflora Present In Coffee Pulp And Husk. Appl. Microbiol. Biotechnol. 42, 756-762, https://doi. org/10.1007/bf00171958 (1995)

33. Wen, X. et al. Large-scale converting waste coffee grounds into functional carbon materials as high-efficient adsorbent for organic dyes. Bioresour. Technol. 272, 92-98, https://doi.org/10.1016/j.biortech.2018.10.011 (2019).

34. Ahmad, M. et al. Biochar as a sorbent for contaminant management in soil and water: A review. Chemosphere 99, 19-33, https://doi. org/10.1016/j.chemosphere.2013.10.071 (2014).

35. Keiluweit, M., Nico, P. S., Johnson, M. G. \& Kleber, M. Dynamic Molecular Structure of Plant Biomass-Derived Black Carbon (Biochar). Env. Sci. Technol. 44, 1247-1253, https://doi.org/10.1021/es9031419 (2010).

36. Chen, B. L. \& Chen, Z. M. Sorption of naphthalene and 1-naphthol by biochars of orange peels with different pyrolytic temperatures. Chemosphere 76, 127-133, https://doi.org/10.1016/j.chemosphere.2009.02.004 (2009).

37. Gong, J., Chen, X. C. \& Tang, T. Recent progress in controlled carbonization of (waste) polymers. Prog. Polym. Sci. 94, 1-32, https:// doi.org/10.1016/j.progpolymsci.2019.04.001 (2019).

38. Poyraz, S., Zhang, L., Schroder, A. \& Zhang, X. Y. Ultrafast Microwave Welding/Reinforcing Approach at the Interface of Thermoplastic. Materials. Acs Appl. Mater. Inter. 7, 22469-22477, https://doi.org/10.1021/acsami.5b06484 (2015).

39. Tang, T., Chen, X. C., Meng, X. Y., Chen, H. \& Ding, Y. P. Synthesis of multiwalled carbon nanotubes by catalytic combustion of polypropylene. Angew. Chem. Int. Ed. 44, 1517-1520, https://doi.org/10.1002/anie.200461506 (2005).

40. Wen, X. et al. Nanosized Carbon Black Combined with Ni2O3 as "Universal" Catalysts for Synergistically Catalyzing Carbonization of Polyolefin Wastes to Synthesize Carbon Nanotubes and Application for Supercapacitors. Environ. Sci. Technol. 48, 4048-4055, https://doi.org/10.1021/es404646e (2014).

41. Lyon, L. A. et al. Raman spectroscopy. Anal. Chem. 70, 341r-361r (1998).

42. Zhu, Y. W. et al. Carbon-Based Supercapacitors Produced by Activation of Graphene. Sci. 332, 1537-1541, https://doi.org/10.1126/ science.1200770 (2011)

43. Chen, X. F. et al. A novel hierarchical porous nitrogen-doped carbon derived from bamboo shoot for high performance supercapacitor. Sci. Rep-Uk 7, 11, https://doi.org/10.1038/s41598-017-06730-x (2017).

44. Chen, C. et al. Three-dimensional scaffolding framework of porous carbon nanosheets derived from plant wastes for highperformance supercapacitors. Nano Energy 27, 377-389, https://doi.org/10.1016/j.nanoen.2016.07.020 (2016).

45. Qian, W. J. et al. Human hair-derived carbon flakes for electrochemical supercapacitors. Energ. Env. Sci. 7, 379-386, https://doi. org $/ 10.1039 / \mathrm{c} 3 e e 43111 \mathrm{~h}(2014)$

46. Zhao, J. et al. Porous 3D Few-Layer Graphene-like Carbon for Ultrahigh-Power Supercapacitors with Well-Defined StructurePerformance Relationship. Adv. Mater. 29, 8, https://doi.org/10.1002/adma.201604569 (2017).

47. Yao, L. et al. Scalable 2D Hierarchical Porous Carbon Nanosheets for Flexible Supercapacitors with Ultrahigh Energy Density. Advanced Materials 30, https://doi.org/10.1002/adma.201706054 (2018).

48. Zhou, L., Cao, H., Zhu, S. Q., Hou, L. R. \& Yuan, C. Z. Hierarchical micro-/mesoporous N- and O-enriched carbon derived from disposable cashmere: a competitive cost-effective material for high-performance electrochemical capacitors. Green. Chem. 17, 2373-2382, https://doi.org/10.1039/c4gc02032d (2015).

49. Long, C. L., Chen, X., Jiang, L. L., Zhi, L. J. \& Fan, Z. J. Porous layer-stacking carbon derived from in-built template in biomass for high volumetric performance supercapacitors. Nano Energy 12, 141-151, https://doi.org/10.1016/j.nanoen.2014.12.014 (2015).

50. Hou, J., Cao, C., Idrees, F. \& Ma, X. Hierarchical porous nitrogen-doped carbon nanosheets derived from silk for ultrahigh-capacity battery anodes and supercapacitors. Acs Nano 9, 2556-2564 (2015)

51. Zhao, Y. F. et al. N-P-O co-doped high performance 3D graphene prepared through red phosphorous-assisted "cutting-thin" technique: A universal synthesis and multifunctional applications. Nano Energy 28, 346-355, https://doi.org/10.1016/j. nanoen.2016.08.053 (2016)

52. Cheng, P. et al. Hierarchically porous carbon by activation of shiitake mushroom for capacitive energy storage. Carbon $93,315-324$, https://doi.org/10.1016/j.carbon.2015.05.056 (2015).

53. Li, Z. et al. Mesoporous nitrogen-rich carbons derived from protein for ultra-high capacity battery anodes and supercapacitors. Energ. Env. Sci. 6, 871-878, https://doi.org/10.1039/c2ee23599d (2013).

54. Hou, L. J. et al. Hierarchically porous and heteroatom self-doped graphitic biomass carbon for supercapacitors. J. Colloid Interf. Sci. 540, 88-96, https://doi.org/10.1016/j.jcis.2018.12.029 (2019).

55. Thangavel, R., Kaliyappan, K., Ramasamy, H. V., Sun, X. L. \& Lee, Y. S. Engineering the Pores of Biomass-Derived Carbon: Insights for Achieving Ultrahigh Stability at High Power in High-Energy Supercapacitors. Chemsuschem 10, 2805-2815, https://doi. org/10.1002/cssc.201700492 (2017).

56. Yu, D. F. et al. Biowaste-Derived Hierarchical Porous Carbon Nanosheets for Ultrahigh Power Density Supercapacitors. Chemsuschem 11, 1678-1685, https://doi.org/10.1002/cssc.201800202 (2018).

57. Sun, L. et al. From coconut shell to porous graphene-like nanosheets for high-power supercapacitors. J. Mater. Chem. A 1, 6462-6470, https://doi.org/10.1039/c3ta10897j (2013).

58. Schneidermann, C. et al. Solvent-Free Mechanochemical Synthesis of Nitrogen-Doped Nanoporous Carbon for Electrochemical Energy Storage. Chemsuschem 10, 2416-2424, https://doi.org/10.1002/cssc.201700459 (2017).

59. Wu, F. M. et al. Hierarchical porous carbon microrods derived from albizia flowers for high performance supercapacitors. Carbon 147, 242-251, https://doi.org/10.1016/j.carbon.2019.02.072 (2019). 


\section{Acknowledgements}

This work was supported by EU-H2020 Marie Sklodowska-Curie Widening Fellowship (MSC-WF, 867436) and the National Science Centre, Poland, within the SONATA BIS Project no. UMO-2015/18/E/ST8/00291.

\section{Author contributions}

X. Liu, S. Zhang, X. Wen and X. Shi prepared the samples and tested their performances; Y. Wen performed TEM observations; X. Wen and X. Liu wrote the manuscript; X. Chen and E. Mijowska helped to discuss the results and revise the manuscript. All authors reviewed the manuscript.

\section{Competing interests}

The authors declare no competing interests.

\section{Additional information}

Supplementary information is available for this paper at https://doi.org/10.1038/s41598-020-60625-y.

Correspondence and requests for materials should be addressed to X.W. or X.C.

Reprints and permissions information is available at www.nature.com/reprints.

Publisher's note Springer Nature remains neutral with regard to jurisdictional claims in published maps and institutional affiliations.

(c) (i) Open Access This article is licensed under a Creative Commons Attribution 4.0 International License, which permits use, sharing, adaptation, distribution and reproduction in any medium or format, as long as you give appropriate credit to the original author(s) and the source, provide a link to the Creative Commons license, and indicate if changes were made. The images or other third party material in this article are included in the article's Creative Commons license, unless indicated otherwise in a credit line to the material. If material is not included in the article's Creative Commons license and your intended use is not permitted by statutory regulation or exceeds the permitted use, you will need to obtain permission directly from the copyright holder. To view a copy of this license, visit http://creativecommons.org/licenses/by/4.0/.

(c) The Author(s) 2020 